\title{
Unrealistic Increases in Wind Speed Explain Reduced Eastern Pacific Heat Flux in Reanalyses ${ }^{\mathscr{O}}$
}

\author{
CHUNLEI LIU ${ }^{\mathrm{a}}$ AND RichaRd P. ALLAN ${ }^{\mathrm{b}}$ \\ Department of Meteorology, University of Reading, and National Centre for Earth Observation, Reading, \\ United Kingdom
}

(Manuscript received 27 September 2017, in final form 10 January 2018)

\begin{abstract}
Tropical eastern Pacific sea surface temperature plays a pivotal role in mechanisms that determine global mean surface temperature variability. In this study, the surface flux contribution to recent cooling of the tropical eastern Pacific is investigated using data from three atmospheric reanalyses with full assimilation of observations, an observation-based net surface energy flux reconstruction, and 15 atmosphere-only climate model simulations. For ERA-Interim, $78 \%$ of the decrease in net surface flux $\left(-0.65 \mathrm{~W} \mathrm{~m}^{-2} \mathrm{yr}^{-1}\right.$ over $1988-$ 2008 ) is explained by the latent heat flux variability. Latent heat flux variability differs between datasets, and this is investigated using a bulk formula. It is found that discrepancies in wind speed change explain contrasting latent heat flux trends across datasets. The significant increase in wind speed of $0.26 \mathrm{~m} \mathrm{~s}^{-1} \mathrm{decade}^{-1}$ over the tropical eastern Pacific in ERA-Interim is not reproduced by satellite or buoy observations or atmosphere-only climate model simulations, casting questions on the reliability of reanalysis-based surface fluxes over the tropical eastern Pacific.
\end{abstract}

\section{Introduction}

Cooling over the tropical Eastern Pacific (TEP) has been identified as an important factor in explaining the mechanisms leading to suppressed global warming at the beginning of the twenty-first century (Easterling and Wehner 2009; Knight et al. 2009; Trenberth and Fasullo 2013; Huber and Knutti 2014; Watanabe et al. 2014; Kosaka and Xie 2013; Meehl et al. 2014; England et al. 2014). Using both the National Oceanic and Atmospheric Administration (NOAA) Twentieth Century Reanalysis (Compo et al. 2011) and the European Centre for Medium-Range Weather Forecasts (ECMWF) interim reanalysis (ERA-Interim) (Dee et al. 2011) as well as model simulations, England et al. (2014) found that the cooling is due to the observed pronounced strengthening

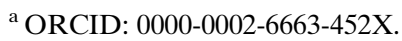

b ORCID: 0000-0003-0264-9447.
}

Supplemental information related to this paper is available at the Journals Online website: https://doi.org/10.1175/JCLI-D-170642.s1.

Corresponding author: Chunlei Liu, c.l.liu@reading.ac.uk in Pacific trade winds, which enhance the ocean heat uptake and the upwelling of the subsurface cold water over the TEP area. Zhou et al. (2016) found that the sea surface temperature (SST) pattern-induced low cloud increase (Norris and Evan 2015) over the TEP region can enhance the shortwave reflection and modify Earth's energy budget. This has been linked to changes in atmospheric stability and can explain increases in climate sensitivity relating to the evolution of SST patterns in response to radiative forcing (Ceppi and Gregory 2017; Andrews and Webb 2018). The cloud feedback on SST changes over the decadal time scale can amplify cooling in the TEP region where air descends. Brown et al. (2014) also showed that cooling may be enhanced in both duration and magnitude by increasing the shortwave reflection (RSW) over the TEP region, where the reduced outgoing longwave radiation (OLR) cannot fully compensate the shortwave reflection, due to the relatively cool marine stratiform clouds present (Klein and Hartmann 1993), reducing the net downward surface energy flux $F_{s}$ and cooling the surface.

On one hand, the cooling TEP will suppress the longwave radiation and the turbulent energy transfer from ocean to the atmosphere, so the net downward energy flux will be increased over this region, as depicted 
by the Atmospheric Model Intercomparison Project (AMIP) model simulations (Liu et al. 2015). On the other hand, increased winds (England et al. 2014) will cause more evaporation, so more latent heat may be lost to the atmosphere and decrease the net downward energy flux. To further understand the mechanisms and driving factors of the TEP cooling, different surface flux data from atmospheric reanalyses, observational reconstructions (Liu et al. 2017), and AMIP phase 5 (AMIP5) simulations are used to study the surface energy flux contributions to the TEP cooling in this study. Considering the imperfect temporal homogeneities in parameterized reanalysis fluxes (Berrisford et al. 2011; Balmaseda et al. 2013; von Schuckmann et al. 2016), the detailed analysis of the reasons causing the spurious changes is conducted in this study using a bulk formula, so as to investigate the role of meteorological variables in determining latent heat flux changes.

\section{Data and method}

The three atmospheric reanalyses used in this study are ERA-Interim (hereinafter ERAINT; Dee et al. 2011; Berrisford et al. 2011), the Japanese 55-year Reanalysis (JRA-55) (Kobayashi et al. 2015), and the Modern Era-Retrospective Analysis for Research and Applications (MERRA2) (Gelaro et al. 2017). Surface fluxes, including the surface shortwave (SW) and longwave (LW) radiation fluxes and the latent heat $(\mathrm{LH})$ and sensible heat $(\mathrm{SH})$ turbulent fluxes, forecasted directly by the reanalyses, are used. The monthly fluxes available for this study are averaged from the forecast every $12 \mathrm{~h}$ for ERAINT, every $6 \mathrm{~h}$ for JRA-55, and every hour for MERRA2. A four-dimensional variational analysis is used in ERAINT and JRA-55, and a three-dimensional variational data assimilation in MERRA2, where data from the full observing system are assimilated. The derived net surface heat fluxes based on the atmospheric energy tendencies and transports of ERAINT and topof-the-atmosphere (TOA) satellite radiation budget data (Allan et al. 2014; Liu et al. 2015, 2017) are also exploited based on results from the Diagnosing Earth's Energy Pathways in the Climate System (DEEP-C) project. DEEP-C takes advantage of the assimilation of full observations in ERAINT and the observed energy budget of the Earth system (Liu et al. 2015), the atmospheric energy transports are mass corrected (Trenberth et al. 1995; Chiodo and Haimberger 2010; Mayer and Haimberger 2012), and the land surface fluxes are adjusted based on the energy budget conservation (Liu et al. 2017) and has applications in a number of previous studies (Williams et al. 2015; Valdivieso et al.
2015; Senior et al. 2016; Roberts et al. 2017). The Clouds and the Earth's Radiant Energy System (CERES) (Loeb et al. 2012) surface radiation fluxes are used to infer the surface turbulent fluxes from DEEP-C net surface flux.

The bulk formula used to calculate the latent heat fluxes at surface is from Singh et al. (2005):

$$
\mathrm{LH}=\rho L C_{E} U\left(Q_{s}-Q_{a}\right),
$$

where $\rho$ is the air density, $L$ is the latent heat of evaporation, $C_{E}$ is bulk transfer coefficient for water vapor (also called the Dalton number) and can be estimated using near-surface wind speed (Bentamy et al. 2003), $U$ is the wind speed at a typical height of $10 \mathrm{~m}, Q_{s}$ is the saturation specific humidity at the surface and can be estimated using SST and sea level pressure, and $Q_{a}$ is the near-surface specific humidity at the atmospheric measurement level and can be empirically estimated from SST and the total column water vapor content [please see Singh et al. (2005) for the detailed descriptions]. The LH estimation is specially designed to use satellite observations. The four input fields are the total column water vapor content (WV), near-surface wind speed, SST, and mean sea level pressure (MSLP), which are all available as analysis time variables from the reanalyses. Considering the good temporal homogeneity of the Special Sensor Microwave Imager (SSM/I) data (Fig. S1 in the supplemental material), the observed $\mathrm{WV}$ and $U$ from SSM/I are employed and the time series is constructed using DMSP $F 8, F 11$, and $F 13$ datasets. The wind speed has a general increasing trend before 2009 , but decreases after 2012 (Fig. S1a). The data from 15 AMIP5 model simulations are also used, with prescribed observed SST and sea ice and realistic radiation forcings (Taylor et al. 2012). The wind speed data from the Tropical Atmosphere Ocean (TAO) moored buoy array (TAO Project Office 2000) are also used for comparison. All datasets are listed in Table 1 with some brief descriptions.

\section{Results}

\section{a. Trends in surface heat flux}

The net surface heat flux trends from ERAINT, DEEP-C, and AMIP5 ensemble mean over 1988-2008 are shown in Fig. 1, together with the ERAINT SST trend. The corresponding area mean anomaly time series over the TEP are also plotted Figs. 1e-h. The trends of ERAINT SST $\left(-0.06 \mathrm{~K}_{\text {decade }^{-1}}\right)$ and net surface flux from DEEP-C $\left(-0.32 \mathrm{~W} \mathrm{~m}^{-2} \mathrm{yr}^{-1}\right)$ and ERAINT $\left(-0.65 \mathrm{~W} \mathrm{~m}^{-2} \mathrm{yr}^{-1}\right)$ show a consistent negative trend over the TEP (Figs. 1a-c). The DEEP-C $F_{s}$ is based on a 
TABLE 1. List of datasets. (Expansions of acronyms are available online at http://www.ametsoc.org/PubsAcronymList.)

\begin{tabular}{|c|c|c|c|}
\hline Dataset & Period (in this study) & Resolution & References \\
\hline \multicolumn{4}{|l|}{ Reconstruct (DEEP-C) } \\
\hline Surface net flux $F_{s}$ & $1985-2015$ & $0.7^{\circ} \times 0.7^{\circ}$ & Liu et al. $(2015,2017)$ \\
\hline CERES & $2001-16$ & $1.0^{\circ} \times 1.0^{\circ}$ & Loeb et al. (2012) \\
\hline \multicolumn{4}{|l|}{$\mathrm{SSM} / \mathrm{I}$} \\
\hline$F 8$ & $1987-2016$ & $0.25^{\circ} \times 0.25^{\circ}$ & Wentz and Spencer (1998) \\
\hline$F 11$ & & & Vila et al. (2010) \\
\hline \multicolumn{4}{|r|}{ (1) } \\
\hline \multicolumn{4}{|c|}{ Atmospheric reanalyses } \\
\hline ERAINT & $1985-2015$ & $0.7^{\circ} \times 0.7^{\circ}$ & Dee et al. (2011) \\
\hline JRA-55 & $1985-2014$ & $0.56^{\circ} \times 0.56^{\circ}$ & Kobayashi et al. (2015) \\
\hline MERRA2 & $1985-2016$ & $0.5^{\circ} \times 0.625^{\circ}$ & Gelaro et al. (2017) \\
\hline TAO buoy & $1990-2017$ & - & TAO Project Office (2000) \\
\hline AMIP5 models & $1985-2008$ & & \\
\hline ACCESS1.0 & & $1.25^{\circ} \times 1.875^{\circ}$ & Bi et al. (2013) \\
\hline CanAM4 & & $2.79^{\circ} \times 2.81^{\circ}$ & Arora et al. (2011) \\
\hline CCSM4 & & $0.94^{\circ} \times 1.25^{\circ}$ & Gent et al. (2011) \\
\hline CMCC-CM & & $0.75^{\circ} \times 0.75^{\circ}$ & Scoccimarro et al. (2011) \\
\hline CNRM-CM5 & & $1.40^{\circ} \times 1.41^{\circ}$ & Voldoire et al. (2013) \\
\hline FGOALS-g2 & & $3.0^{\circ} \times 2.81^{\circ}$ & Li et al. (2013) \\
\hline GFDL CM3 & & $2.0^{\circ} \times 2.5^{\circ}$ & Delworth et al. (2006) \\
\hline GISS-E2-R & & $2.0^{\circ} \times 2.5^{\circ}$ & Schmidt et al. (2014) \\
\hline HadGEM2-A & & $1.25^{\circ} \times 1.875^{\circ}$ & Collins et al. (2011) \\
\hline INM-CM4.0 & & $1.5^{\circ} \times 2.0^{\circ}$ & Volodin et al. (2010) \\
\hline IPSL-CM5A-LR & & $1.89^{\circ} \times 3.75^{\circ}$ & Dufresne et al. (2013) \\
\hline MIROC5 & & $1.39^{\circ} \times 1.41^{\circ}$ & Watanabe et al. (2011) \\
\hline MPI-ESM-LR & & $1.85^{\circ} \times 1.875^{\circ}$ & Raddatz et al. (2007) \\
\hline MRI-CGCM3 & & $1.11^{\circ} \times 1.13^{\circ}$ & Yukimoto et al. (2012) \\
\hline NorESM1-M & & $1.89^{\circ} \times 2.5^{\circ}$ & Zhang et al. (2012) \\
\hline
\end{tabular}

combination of satellite data and ERAINT atmospheric energy transports but does not use the simulated surface fluxes. While both datasets display a negative trend in downward net heat flux over the TEP, the DEEP-C trend is smaller in magnitude than that of ERAINT (Figs. 1f,g). The strong negative trend can also be seen from JRA-55 data (Fig. S2a in the supplemental material), but is weak in MERRA2 data (Fig. S2b) and not present in AMIP5 ensemble mean simulations (Fig. 1d). Both trends from ERAINT and JRA-55 (Figs. 1c and S2a) show similar spatial patterns, with negative trends over the central Indian Ocean and western and eastern Pacific but positive trends in the northeastern Pacific. A contrasting pattern is produced by MERRA2: the trend over the northeastern Pacific is negative but positive over most of the TEP area. Trend patterns in SST (Fig. 1a) and AMIP5 ensemble mean simulated $F_{s}$ (Fig. 1d) are anticorrelated, indicating that reducing SST leads to reduced heat loss to the atmosphere and thus more surface flux into the ocean (increased $F_{s}$ ). In contrast, this is not seen in DEEP-C (Fig. 1b) and ERAINT (Fig. 1c). Although the input data used to generate the DEEP-C product are not fully coupled, these data are considered the best representation of the coupled system available to us. The errors can be introduced from incomplete coverage, biases, and model inadequacies during observational input to ERAINT, but it is representative of the coupled system, in which heat fluxes can drive changes in SST (e.g., reduced $F_{S}$ can cool the ocean and reduce SST).

The deseasonalized anomaly time series of $F_{s}$ and its four components (SW, $\mathrm{LW}, \mathrm{SH}$, and $\mathrm{LH}$ ) over the TEP are plotted in Figs. 1g,h and S2c,d; the reference period for the anomaly calculation is from 2001 to 2008. It is clear that the LH variation dominates the $F_{s}$ variability in three atmospheric reanalyses and the AMIP5 ensemble mean. The LH trend follows the corresponding $F_{s}$ trend, and the correlation coefficients $r$ between LH and $F_{s}$ over 1988-2008 for ERAINT, JRA-55, MERRA2, and the AMIP5 ensemble mean are 0.97, $0.94,0.90$, and 0.96 , respectively; the LH trend magnitudes are $78 \%, 98 \%, 169 \%$, and $44 \%$ of the $F_{s}$ trends for ERAINT, JRA-55, MERRA2, and the AMIP5 ensemble mean, respectively. The turbulent fluxes ( $\mathrm{SH}$ and $\mathrm{LH})$ are also derived from the difference of the DEEP-C net surface energy fluxes and the CERES surface radiation fluxes, and the anomaly time series is plotted in Fig. 1f. The corresponding correlation coefficient between turbulent flux and $F_{s}$ over $2002-15$ is 0.98 . It is apparent that $\mathrm{SW}$ radiation and $F_{S}$ variability are also 

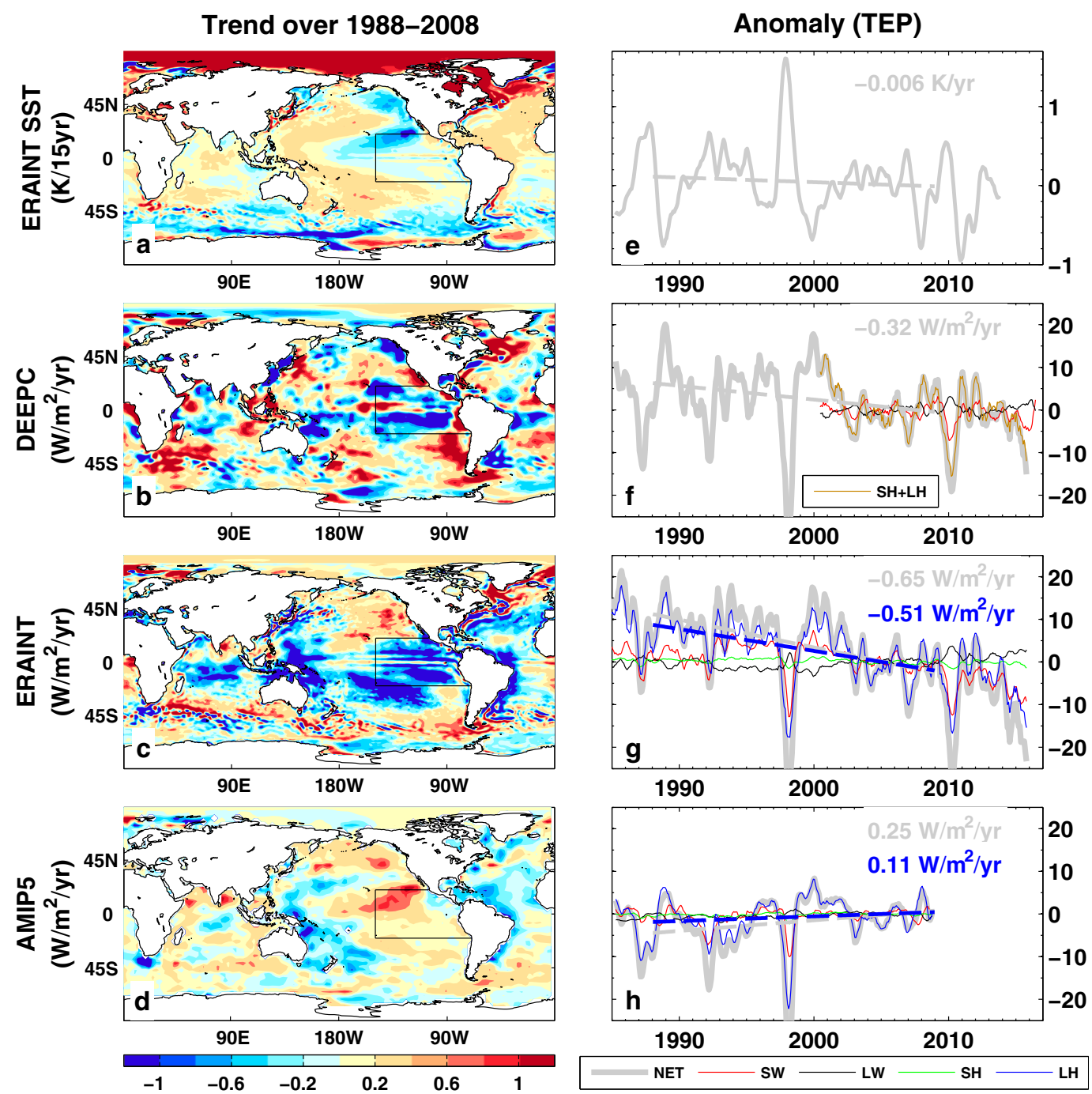

FIG. 1. The trend of (a) SST and (b)-(d) net surface flux over 1988-2008. (e)-(h) The corresponding area mean anomaly time series over the TEP [marked area in (a)-(d) from $20^{\circ} \mathrm{N}-20^{\circ} \mathrm{S}, 150^{\circ} \mathrm{W}$ to the west coast of Central America]. (g),(h) Four components of $F_{s}$ are also plotted, and (f) the SW and LW fluxes from CERES are plotted, together with the turbulent flux derived from the difference between DEEP-C net surface flux and CERES radiation fluxes. The reference period is 2001-08. The datasets are from ERAINT, DEEP-C, and AMIP5 15-member ensemble. All fluxes are downward positive. All lines are 6-month running means and some linear trends are also displayed.

well correlated $(r=0.69,0.72,0.73$, and 0.56 for ERAINT, JRA-55, MERRA2, and AMIP5 ensemble mean, respectively), but the SW radiation trend is generally smaller than the $F_{s}$ trend. The corresponding SW radiation trend contribution to the $F_{s}$ trend is $22 \%$ for ERAINT and $11 \%$ for JRA-55, and the contribution of $31 \%$ in AMIP5 ensemble mean is relatively strong. The SW radiation trend in MERRA2 is of opposite sign to the $F_{s}$ trend. All these correlation coefficients are significant based on the two-tailed test using Pearson critical values at the level of $5 \%$, and the trends (except for the LH trend of AMIP5) are also significant using the Mann-Kendall test at a significance level of 0.05 (Hipel and McLeod 1994), which emphasizes that the evaporation dominates variability and trends in surface fluxes in the equatorial eastern Pacific.

Both ERAINT and JRA-55 show strong downward $F_{s}$ trends of 0.65 and $0.50 \mathrm{~W} \mathrm{~m}^{-2} \mathrm{yr}^{-1}$ over 1988-2008, respectively. MERRA2 also shows a weak negative trend in $F_{s}\left(-0.13 \mathrm{~W} \mathrm{~m}^{-2} \mathrm{yr}^{-1}\right)$ and $\mathrm{LH}\left(-0.22 \mathrm{~W} \mathrm{~m}^{-2} \mathrm{yr}^{-1}\right)$. Considering the global changes may include spurious jumps, as a very crude adjustment, the global mean $F_{s}$ trend over the same period shown in Fig. S2e is 
removed, and the corresponding $F_{s}$ trends over the TEP are $-0.53,-0.29$, and $-0.35 \mathrm{~W} \mathrm{~m}^{-2} \mathrm{yr}^{-1}$ for ERAINT, JRA-55, and DEEP-C, respectively. They are all significant using the Mann-Kendall test at a significance level of 0.05 . Considering the ocean heat capacity of $4.2 \times 10^{6} \mathrm{~J} \mathrm{~K}^{-1} \mathrm{~m}^{-2} \mathrm{~m}^{-1}$, the mean mixing depth of $100 \mathrm{~m}$ over the eastern Pacific (Roberts et al. 2017) and $F_{s}$ is $3 \mathrm{~W} \mathrm{~m}^{-2}$ lower in the 2000 s versus the $1990 \mathrm{~s}$; the estimated temperature change $\Delta T \approx-2.3 \mathrm{~K}$ is too large considering the observed ocean temperature change over the TEP area (Fig. 1e). This suggests that either the trends are unrealistic or changes in ocean heat transport convergence offset these surface heat flux changes. It is noticed that there are discontinuities in global area mean $F_{s}$ time series of MERRA2 (Fig. S2e): it has a step change near 1992, a large negative trend between 1992 and 2008 , and an anomalous positive trend after 2009. Since the DEEP-C global mean net surface flux is well constrained by the TOA satellite observations (Allan et al. 2014) and the zero global atmospheric energy convergence (Liu et al. 2015, 2017), the global mean $F_{s}$ from the DEEP-C product can be regarded as realistic. It is also noticed both $F_{s}$ and LH trends from MERRA2 over the TEP differ with the other two atmospheric reanalyses.

The contributions of SW fluxes to the net surface flux trends over the TEP are significant for the later periods $\left(-0.50 \mathrm{~W} \mathrm{~m}^{-2} \mathrm{yr}^{-1}\right.$ for $1995-2015$ in ERAINT and $-0.42 \mathrm{~W} \mathrm{~m}^{-2} \mathrm{yr}^{-1}$ over $2000-15$ for JRA-55), consistent with evidence of increased low cloud cover (LCC) (Norris and Evan 2015; Zhou et al. 2016). However, for the longer 1988-2008 period, LH is found to dominate the changes in $F_{s}$.

\section{b. Sensitivity of latent heat flux to atmospheric variables}

Since the LH change dominates the $F_{s}$ variability over the TEP in three atmospheric reanalyses, observation and AMIP5 simulation ensemble mean, it is necessary to investigate the driver for the LH change. To do this, the bulk formula developed by Singh et al. (2005) is employed to compute LH. This bulk formula is designed for the application of satellite observations so only four meteorological variables are required for input: SST, MSLP, WV, and $U$ (near-surface wind speed, generally at $10 \mathrm{~m}$ ). For the sensitivity test, climatologies of four fields are applied, and each time-varying individual field is subsequently substituted into the bulk formula to isolate the contribution of the determinant variables. Effects on LH trend from the different SST and MSLP datasets are similar, so are not shown and discussed here. An unrealistic decline in global area mean ERAINT WV around 1991-93 compared with SSM/I observations (Allan et al. 2014; Allan 2017) was removed by adjusting values prior to 1993 to force agreement with the global mean SSM/I WV anomalies over the 1988-92 period. The influence of water vapor and wind speed changes on LH variability (downward defined as positive) is estimated for ERAINT, SSM/I, and AMIP5 in Fig. 2. For ERAINT the generally positive global net downward LH trend in Fig. 2a is due to the increasing WV (Fig. 3a), which decreases the surface evaporation, but the effect on the LH trend over the TEP region is weak. The estimated influence of changes in $U$ on surface evaporation is substantial (Fig. 2b). The strong negative trend in downward $\mathrm{LH}$ over the central and eastern Pacific is driven by the wind speed variability. After combining $U$ and $\mathrm{WV}$, the trend pattern of LH is similar to that using $U$ alone (Fig. 2c). When all four actual fields of ERAINT are used, the trend pattern is still dominated by that using the wind speed alone (Fig. 2d) and the LH trend of $-0.20 \mathrm{~W} \mathrm{~m}^{-2} \mathrm{yr}^{-1}$ over the TEP is still significant (the corresponding global trend of $-0.02 \mathrm{~W} \mathrm{~m}^{-2} \mathrm{yr}^{-1}$ is small and insignificant), indicating that the wind speed is the driver of negative LH trend over the TEP in ERAINT. Compared with the LH trend from direct model output (Fig. 2e), it can be seen that the model-generated LH trend has more extensive negative trend areas over the whole tropical region, and the $\mathrm{LH}$ trend over the TEP is also stronger $\left(-0.51 \mathrm{~W} \mathrm{~m}^{-2} \mathrm{yr}^{-1}\right.$; see Fig. $\left.1 \mathrm{~g}\right)$. After removing the global LH trend, the corresponding $\mathrm{LH}$ trend of $-0.39 \mathrm{Wm}^{-2} \mathrm{yr}^{-1}$ over the TEP area is roughly consistent with $-0.18 \mathrm{~W} \mathrm{~m}^{-2} \mathrm{yr}^{-1}$ from the bulk formula, and their correlation coefficient is 0.81 over 1988-2008 (Fig. S3a in the supplemental material).

To check the effect of the data type used in this study on the LH estimation, the results from both the daily and monthly data; from the analysis and forecast fields of SST, MSLP, WV, and $U$; and from the estimated and model output specific humidity were all tested. The estimated LH trends over the TEP area from 1988 to 2008 are $-0.23,-0.22$, and $-0.20 \mathrm{~W} \mathrm{~m}^{-2} \mathrm{yr}^{-1}$ using the daily forecast, monthly forecast, and monthly analysis fields of ERAINT, respectively. Since there is no direct specific humidity output available for us from ERAINT, the JRA-55 data are used for the sensitivity test. The estimated $\mathrm{LH}$ trends are -0.35 and $-0.46 \mathrm{~W} \mathrm{~m}^{-2} \mathrm{yr}^{-1}$ using the estimated specific humidity from WV and SST and the reanalysis specific humidity, respectively. Therefore, the impact of these factors on the LH trend over the TEP area is small, so it is assumed that the discrepancies in spatial structure and values between LH estimates from bulk formula and direct model output are mainly due to different bulk formula used in the LH calculation. The bulk formula of Singh et al. (2005) is applied to the monthly data in this study. 

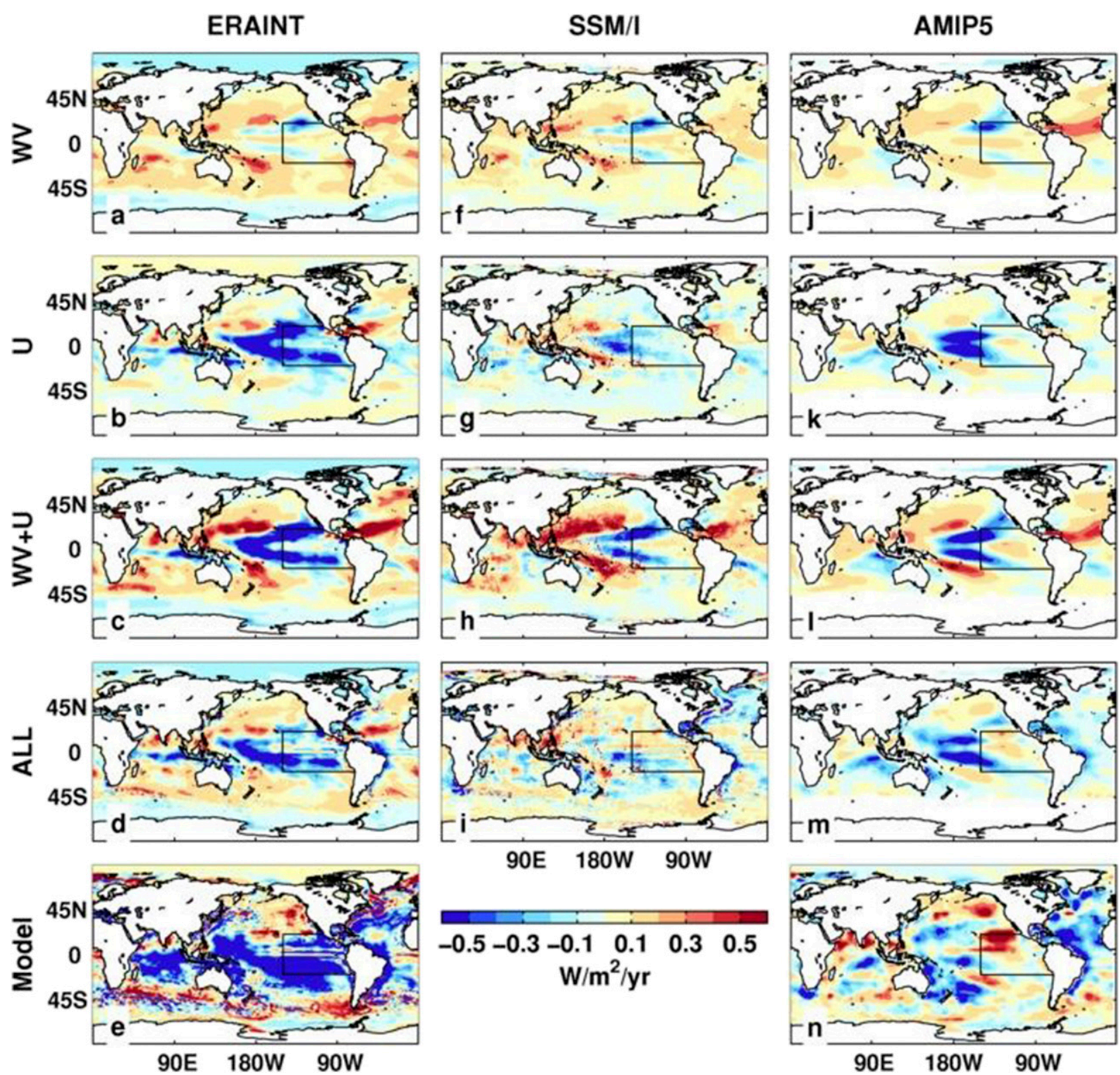

FIG. 2. Sensitivity test of LH trend using bulk formula over 1988-2008. The climatologies of SST, MSLP, WV, and wind speed from ERAINT are used at first, then the corresponding climatologies are replaced by (a) ERAINT WV, (b) ERAINT wind speed, (c) ERAINT WV and wind speed, (d) all four fields from ERAINT, (f) SSM/I WV, (g) SSM/I wind speed, (h) SSM/I WV and wind speed, and (i) WV and wind speed from SSM/I and SST and MSLP from ERAINT. (e) The LH trend directly from ERAINT. The same method is applied to each of the 15 AMIP5 models, and (j)-(m) the ensemble means are plotted. (n) The mean LH trend from 15 AMIP5 model simulations.

Since only WV and $U$ are available from SSM/I data, the climatologies of four fields from ERAINT are used at first, and then the corresponding climatologies are replaced by SSM/I WV (Fig. 2f) and SSM/I $U$ (Fig. 2g), respectively. The spatial pattern of the SSM/I WV effect on LH trend is similar to that of ERAINT WV. The SSM/I wind speed variability also generates negative downward LH trend over the TEP region, but it is relatively weak compared with that from
ERAINT wind speed (Figs. 2b,g). When combining SSM/I WV and $U$ together, the negative trend over the TEP area is greatly reduced (Fig. $2 \mathrm{~h}$ ), and it is further smoothed out after the actual fields of WV and $U$ from SSM/I and SST and MSLP from ERAINT are used. This indicates that the SSM/I wind speed variability is not large enough to produce the strong negative LH trend, and this will be further investigated in next section. 


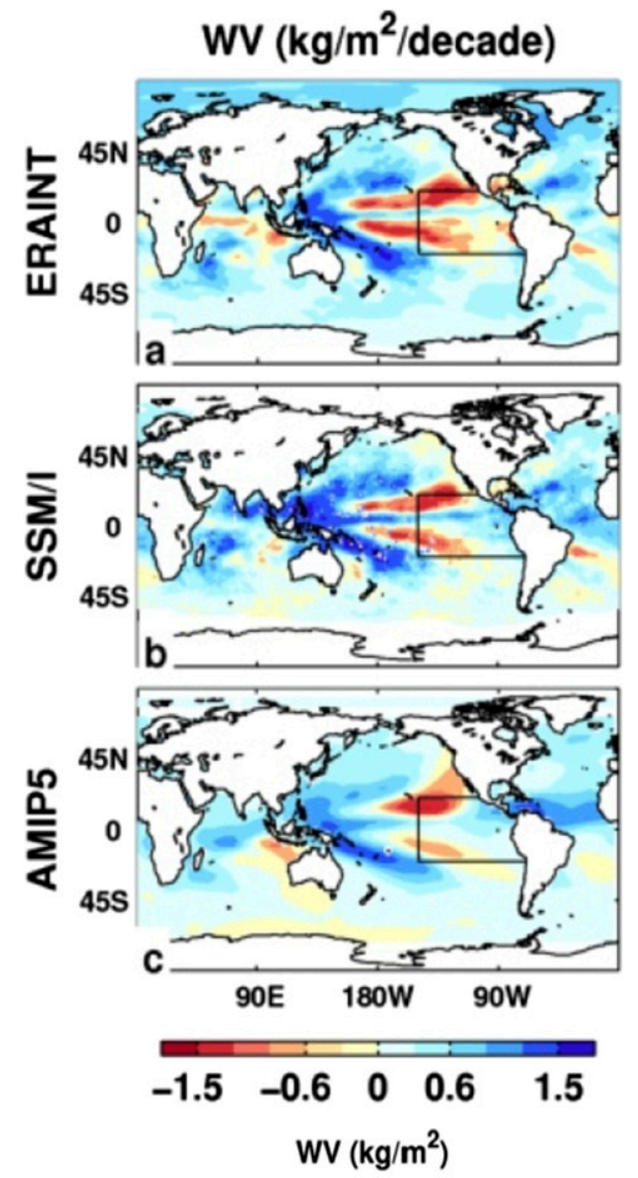

Wind speed (m/s/decade)
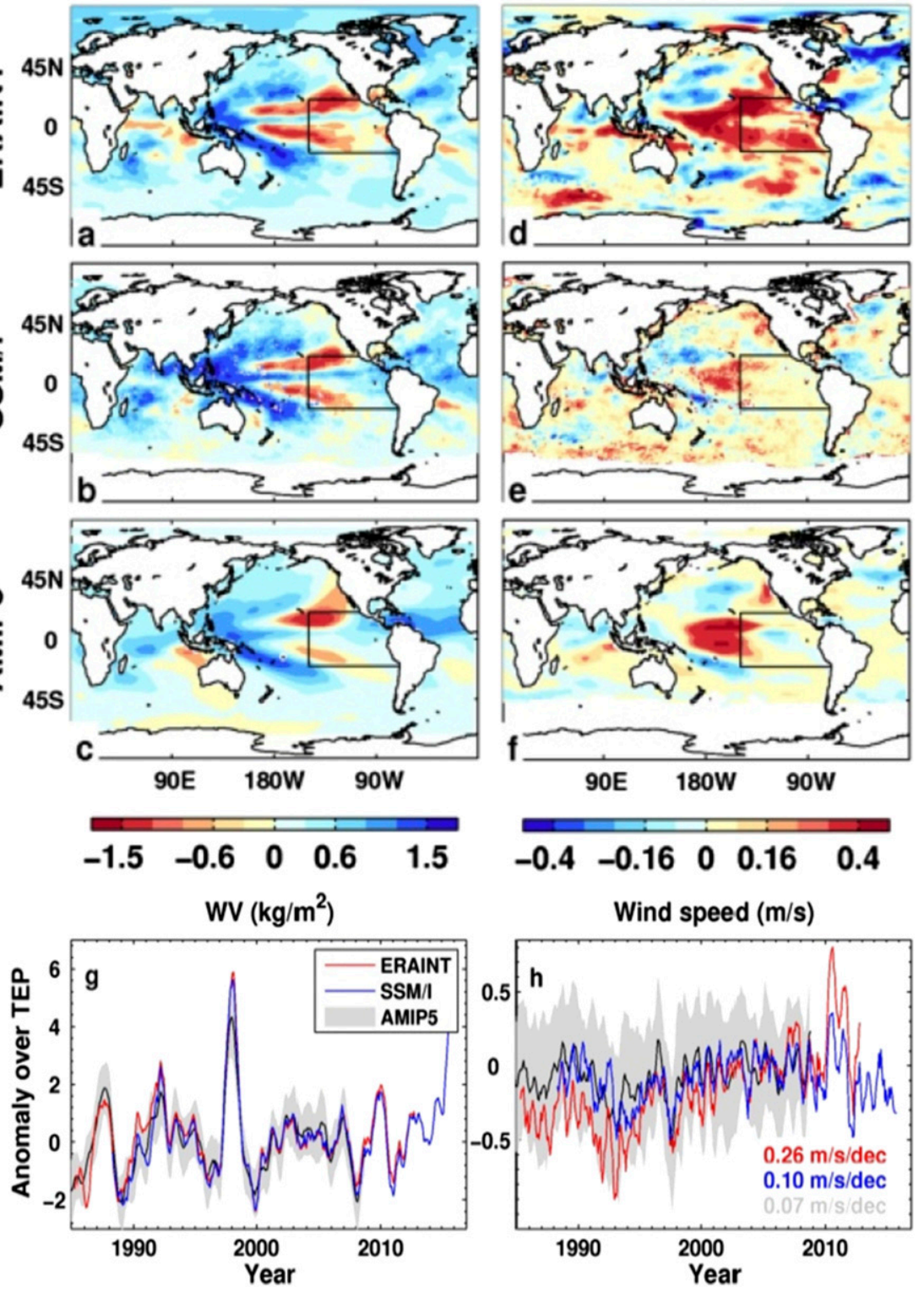

FIG. 3. Trends of (a)-(c) WV and (d)-(f) wind speed over 1988-2008 from ERAINT, SSM/I, and the AMIP5 ensemble mean. Corresponding deseasonalized time series of area mean (g) WV and (h) wind speed over the TEP. The shaded areas of AMIP5 are 15-member ensemble mean (solid black line) plus or minus one standard deviation. The reference period is 2001-08 for anomaly calculation. The wind speed trends over 1988-2008 are also displayed in (h).

For the AMIP5 data, the above method is applied to each member and the trends are interpolated into a common grid of $3^{\circ} \times 3^{\circ}$; the ensemble mean results are shown in Figs. 2j-m. The spatial pattern of the mean effect of WV on LH trend (Fig. 2j) is similar to those in Figs. 2a,f, implying similar WV trend in three datasets. The wind speed effect is strong in the central Pacific, but weak over the TEP area where the LH trend is overall positive (reduced evaporative flux). The combined WV and $U$ effect enhances the positive trend over the TEP region, although the spatial patterns over other regions are similar between these three datasets. After all four fields are used (Fig. $2 \mathrm{~m}$ ), the trend over the TEP is very weak $\left(\sim-0.02 \mathrm{~W} \mathrm{~m}^{-2} \mathrm{yr}^{-1}\right)$ and insignificant (Fig. S3b). The mean LH trend from the ensemble mean of 15 AMIP5 model simulations is shown in Fig. 2n, which 
shows similar but stronger spatial pattern compared to that from bulk formula (Fig. $2 \mathrm{~m}$ ) (spatial correlation $r=$ $0.61)$; in particular, the $\mathrm{LH}$ trend of $0.11 \mathrm{~W} \mathrm{~m}^{-2} \mathrm{yr}^{-1}$ over the TEP area (Fig. 1h) is stronger, but still insignificant (Fig. S3b). This implies that the application of the bulk formula to the monthly data may smooth the LH calculation, even though the global spatial patterns are still consistent (Figs. 2m,n). Therefore, according to the sensitivity test using bulk formula and direct model output, it is clear that the bulk formula used in this study can reasonably capture aspects of the main features of the corresponding data. Furthermore, these sensitivity tests highlight discrepancies in $\mathrm{LH}$ trends between datasets over the TEP area, and the overall sign of the LH trend depends primarily on the wind speed variability.

\section{c. Evaluation of water vapor and wind speed trends}

To understand the influence of $\mathrm{WV}$ and $U$ variability on LH and surface heat flux trend patterns, the trends of WV and $U$ from ERAINT, SSM/I, and the AMIP5 ensemble mean over 1988-2008 are investigated (Fig. 3). For WV trends (Figs. 3a-c), the spatial patterns from the three datasets are similar; the trend pattern from ERAINT WV is in close agreement with SSM/I, which is unsurprising since this is assimilated by ERAINT over the ice-free oceans. Both JRA-55 and MERRA2 show strong positive trends in the central and eastern tropical Pacific (Figs. S4a,b in the supplemental material). The similarity of the WV trend across datasets can also be clearly seen from the area mean anomaly time series over the TEP (Figs. 3g and S4e). The WV trends from the AMIP5 ensemble mean (Fig. 3c) and 15 members (Fig. S5 in the supplemental material) are also similar. The LH trend spatial pattern in Figs. 2a,f,j and the WV trend spatial pattern in Figs. 3a-c are similar, confirming that the higher $\mathrm{WV}$ in the atmosphere column will suppress local evaporation.

The wind speed trends contrast across datasets. Both ERAINT (Fig. 3d) and JRA-55 (Fig. S4c) show strong positive wind speed trends over the central and eastern Pacific, but positive trends from both SSM/I and MERRA2 are much weaker (Figs. 3e and S4d). This can also be clearly seen from the area mean wind speed anomaly time series over the TEP as shown in Figs. $3 \mathrm{~h}$ and S4f (good agreement between 1995 and 2008 is due to the selection of the reference period of 2001-08). The trends over 1988-2008 are both $0.26 \mathrm{~m} \mathrm{~s}^{-1}$ decade $^{-1}$ for ERAINT and JRA-55, larger than those from SSM/I $\left(0.10 \mathrm{~m} \mathrm{~s}^{-1}\right.$ decade $^{-1}$; Fig. 3e $)$ and the AMIP5 ensemble mean $\left(0.07 \mathrm{~m} \mathrm{~s}^{-1}\right.$ decade $^{-1} ;$ Fig. 3f). Although the trends are different, variability is similar (Figs. 3h and S4f). All AMIP5 members show strong wind speed trends in the central Pacific, but weak trends over the TEP (Fig. S6 in the supplemental material).

To see if the MSLP drives the wind changes, the MSLP trend over 1988-2008 and the multiannual mean were compared (Fig. S7 in the supplemental material). The similarity of the trend structure in ERAINT (Fig. S7a) and JRA-55 (Fig. S7b) in the meridional direction indicates similar gradient changes of MSLP between subtropics and equator, which may explain the agreement of wind speed trend structure between them. The relatively weak trend of the subtropical high south of the TEP in MERRA2 (Fig. S7c) and AMIP5 (Fig. S7d) indicates weak gradient changes of MSLP between the south subtropics and equator, which may explain the weak wind speed trend over the TEP area. Therefore, although the MSLP change over the TEP area has a very small direct effect on the LH trend estimation, the MSLP spatial structure difference can affect the pressure gradient and further change the wind speed. In addition, de Boisséson et al. (2014) found good agreement for zonal wind speed trends over the tropical Pacific between ERAINT and observations but noted that the discontinuities between different satellite products are not taken into account, such as the big jumps between the European Remote Sensing Satellite-2 (ERS-2) and the Quick Scatterometer (QuikSCAT) near 2000 in their Fig. 2a and between ERS-2 and Envisat near 2003 in their Fig. 2b. Different conclusions may be obtained if these discontinuities are considered.

\section{d. Comparison with buoy observations}

The large discrepancies in wind speed changes over the TEP cast doubt on the reliability of the wind speed in these datasets. To further check the wind speed quality, data from TAO moored buoy array $\left(9^{\circ} \mathrm{N}-8^{\circ} \mathrm{S}, 140^{\circ}-\right.$ $105^{\circ} \mathrm{W}$ ) are used in this study for comparison (TAO Project Office 2000). There are 27 buoys working in this area; they are all calibrated before deployment and there is no postdeployment calibration involved. (Data quality control information can be found at http:// tao.ndbc.noaa.gov/proj_overview/qc_ndbc.shtml.) The locations of the buoys are plotted in Fig. 4a (colored dots represents the wind speed trend from the buoy), which is an enlargement of Fig. 3d showing the ERAINT wind speed trend. From January 1990 to December 2015, there are 312 months; the minimum coverage period from start to end month over all stations is 202 months at station $8^{\circ} \mathrm{N}, 110^{\circ} \mathrm{W}$ (Fig. S8a in the supplemental material), so all buoy records span at least $65 \%$ of the record length. However, there are considerable gaps in the buoy time series: the minimum fraction of the data coverage over $1990-2015$ is about $30 \%$ at the station 

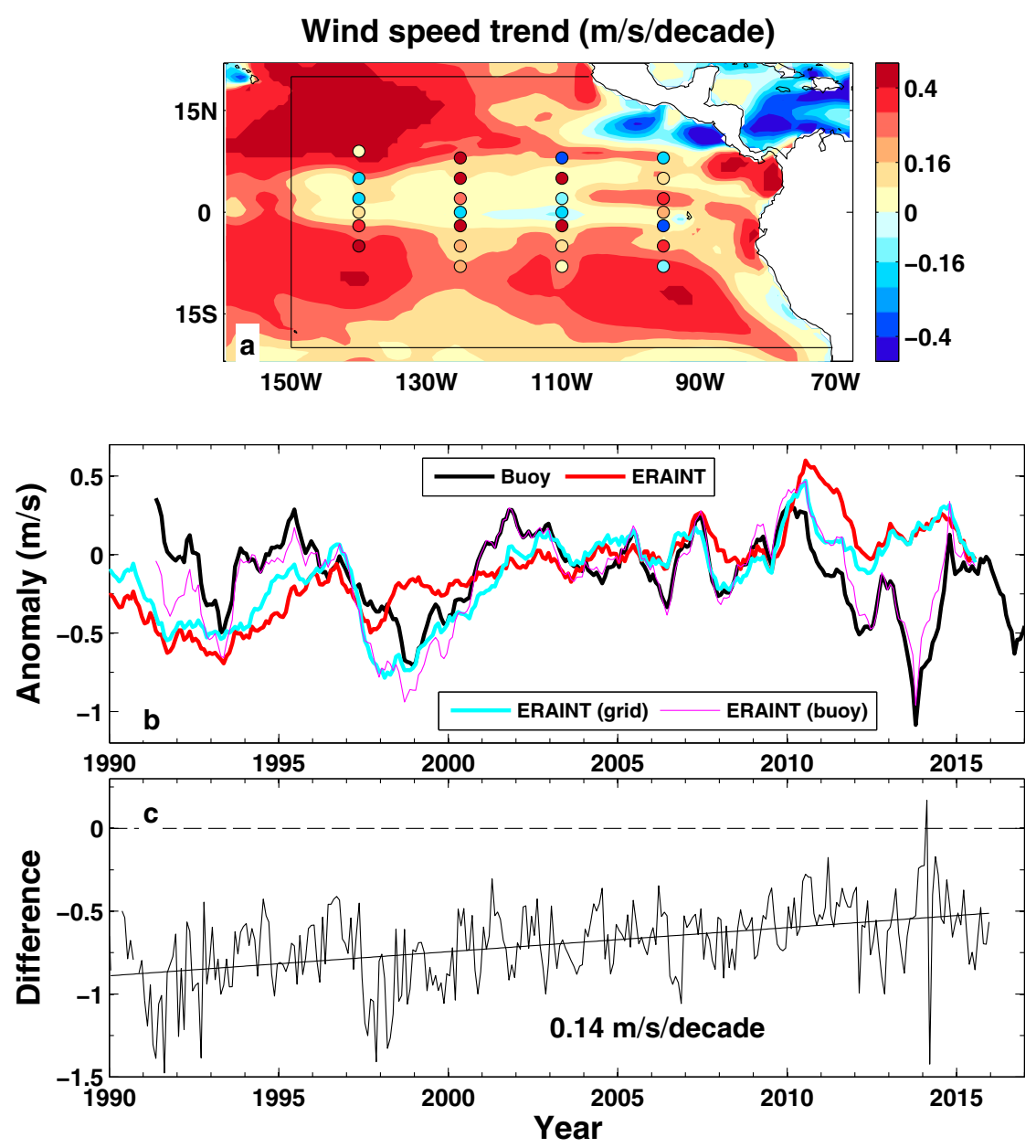

FIG. 4. (a) Wind speed trend from ERAINT (enlargement of the marked area in Fig. 3d). Colored dots indicate 27 TAO buoy locations and wind speed trends. (b) Deseasonalized wind speed anomaly (relative to 2001-08 period) time series from buoy stations (composite, thick black line), ERAINT area-weighted mean over the TEP (thick red line), ERAINT mean from grid points nearest to buoy stations including all data points (thick cyan line, no area weighting), and the ERAINT mean including data points where the buoy station has the valid data (magenta line, no area weighting). All lines are 12 month running mean. (c) The time series of mean wind speed bias between ERAINT and buoy data using consistent spatiotemporal sampling. The trend of $0.14 \mathrm{~m} \mathrm{~s}^{-1}$ decade $^{-1}$ over 1990-2015 is also displayed.

$5^{\circ} \mathrm{N}, 125^{\circ} \mathrm{W}$ (Fig. S $8 \mathrm{~b}$ ) and the mean fraction is $50 \%$. At each station, the anomaly is calculated by removing the monthly mean (over 2001-08), which is calculated if the total number of months is $\geq 2$. The wind speed anomaly time series is plotted in Fig. S9 of the supplemental material, but the actual number of valid buoy data points is not well reflected due to the smoothing of six month running mean. The wind speed trends from individual buoy records (Table S1 in the supplemental material) are generally insignificant: only 9 out of 27 display significant trends and 8 of these are positive (see also Fig. S9) while the composite trend of $-0.05 \mathrm{~m} \mathrm{~s}^{-1}$ decade $^{-1}$ is small and insignificant; 21 out of 27 wind speed trends calculated from ERAINT grid points nearest to the corresponding buoy stations (bottom right of the matrixed Table S1) are positive and significant, and the composite trend of $0.28 \mathrm{~m} \mathrm{~s}^{-1}$ decade $^{-1}$ is also significant. When the ERAINT gridbox time series are sampled to mimic the intermittent buoy time series (bottom center of the matrixed Table S1), 16 out of 27 of the trends remain positive and significant and the composite trend of $0.25 \mathrm{~m} \mathrm{~s}^{-1}$ decade $^{-1}$ is significant. Therefore, although intermittent data coverage reduces the significance of trends, there are more robust positive trends in the ERAINT data when sampled to mimic the buoy spatial and temporal coverage. 
Mean wind speed variability in the TEP for 1990-2008 is displayed in Fig. $4 \mathrm{~b}$ for ERAINT using a variety of spatial and temporal sampling strategies and the composite of the buoy measurements. The fraction of valid buoy data in each month increases steadily from about 1990 to 2000 and then becomes stable afterward while there is a drop between 2011 and 2015 (Fig. S8c). Variability in mean ERAINT wind speed over the TEP (Fig. 4b, thick red line) is similar to when only grid boxes corresponding to the buoy locations are sampled (cyan line). This indicates that the area mean from the buoy spatial coverage is representative of the wider, completely sampled region; trends over the 1990-2015 period are significant (based on the Mann-Kendall test at a significance level of 0.05 ) and positive for both, although the trend is larger for the TEP region $\left(0.34 \mathrm{~m} \mathrm{~s}^{-1}\right.$ decade $\left.^{-1}\right)$ than for the buoy grid points $\left(0.28 \mathrm{~m} \mathrm{~s}^{-1}\right.$ decade $\left.^{-1}\right)$. The composite wind speed time series from buoys (Fig. 4b, thick black line) displays an insignificant negative trend of $-0.05 \mathrm{~m} \mathrm{~s}^{-1}$ decade $^{-1}$ for 1990-2008. Sampling ERAINT to also match the temporal coverage of the buoys (magenta line) alters the time series substantially demonstrating the substantial effect of incomplete observational coverage. Agreement between ERAINT buoy spatial and temporal sampling (magenta line) and the buoy time series variability is markedly improved $(r=0.92)$, indicating successful assimilation of the observational variability by ERAINT. However, the ERAINT composite (magenta line) trend remains positive $\left(0.25 \mathrm{~m} \mathrm{~s}^{-1}\right.$ decade $\left.^{-1}\right)$ and substantially larger than the corresponding trend from the buoy data. The corresponding plot for $\mathrm{LH}$, similar to Fig. $4 \mathrm{~b}$, is shown in Fig. S8d for reference.

The ERAINT minus buoy wind speed difference using consistent spatiotemporal sampling (Fig. 4c) depicts an increasing trend $\left(0.14 \mathrm{~m} \mathrm{~s}^{-1}\right.$ decade $^{-1}$ over 1990 2015), which contributes about $50 \%$ to the overall trend of ERAINT wind speed over the TEP. Thus, the discrepancy between the buoy and ERAINT wind speed trends cannot easily be explained by the variable buoy coverage. It is not currently clear how the assimilation of data from an evolving observing system simply explains this discrepancy and further investigation is merited. The remaining difference is apparently associated with the fact the influence of the assimilation declines rapidly with distance from the buoy as pointed out by Josey et al. (2014). Based on the comparison and analysis, the area mean from the limited buoy spatial coverage (cyan line in Fig. 4b) is representative of that over the wider, completely sampled TEP area (red line in Fig. 4b), and the intermittent buoy wind speed variability is well assimilated into the ERAINT model. However, increases in the ERAINT minus buoy wind speed, when consistently sampled in space and time, indicate that increases in wind speed and therefore also surface latent heat flux are unrealistic and so the large decreases in net downward energy flux into the tropical eastern Pacific are questionable.

\section{Conclusions}

Cooling of the surface ocean over the tropical eastern Pacific influences the global mean rate of surface temperature change (Kosaka and Xie 2013; Trenberth and Fasullo 2013; England et al. 2014). To understand the mechanism of the cooling, numerous studies have been conducted (Meehl et al. 2011; Hansen et al. 2011; Guemas et al. 2013; Katsman and van Oldenborgh 2011; Solomon et al. 2010; Kaufmann et al. 2011; Norris and Evan 2015; Brown et al. 2014; Zhou et al. 2016). Motivated by a discrepancy between observation-based estimates of surface heat flux changes and simulations from atmosphere-only models over the TEP (Liu et al. 2015), an investigation of the causes of the surface energy flux is conducted using data from three atmospheric reanalyses, 15 AMIP5 model simulations, and the DEEP-C observation-based reconstruction. It is found that the net downward surface flux change over the TEP is dominated by the LH variability, and the trend is significantly negative in ERAINT, JRA-55, and the DEEP-C data. The negative trend over the TEP from DEEP-C is not as strong as that from ERAINT (Figs. 1f,g) as a result of the contrasting methodologies. In contrast, the $F_{s}$ and LH trends in the AMIP5 ensemble mean show positive trend over the TEP region, and the spatial pattern is closely related to the SST pattern, indicating that SST changes are driving heat flux changes in the AMIP5 model simulations. Since the atmosphere simulations do not permit a coupled response to the surface fluxes, it is possible that they are missing an important mechanism yet the negative trends depicted by the reanalysis-based estimates appear unrealistically large.

To investigate the realism and cause of the implied changes in surface heat flux, sensitivity tests using turbulent heat flux bulk formula are applied. These indicate that the LH changes depicted by ERAINT are dominated by wind speed changes, which show increasing trends over the eastern Pacific. This wind speed trend is very weak in SSM/I satellite observations and is absent in AMIP5 ensemble mean simulations. After further comparison with buoy observations, it is found that few buoy stations show significant positive wind speed trends, although the corresponding composite trends from ERAINT grid points nearest to the stations are significantly positive. The variable spatial coverage of 
the buoy wind speed is assimilated by ERAINT and the buoy coverage is shown to reasonably represent the TEP area mean wind speed (cyan line in Fig. 4b). However, an increase in ERAINT minus buoy wind speed, when consistently sampled in space and time, suggest that the increases in wind speed depicted by ERAINT are overestimated. This further implies that increased evaporative fluxes and reduced downward heat flux trends depicted by ERAINT and other datasets may be unrealistic. The discrepancies between different datasets cast questions on the reliability of the reanalyzed surface fluxes over the tropical eastern $\mathrm{Pa}$ cific area. In AMIP5 simulations, models are forced by SST, so the SST decrease over the TEP suppresses the evaporation and reduce the upward LH flux, enhancing the downward net surface flux. In the atmospheric reanalysis, such as ERAINT the dominant contribution of strong wind speed trend to the LH flux changes is evident. The strong ERAINT LH trend is unrealistic considering the observed temperature changes over the TEP region (based upon energy budget arguments) and comparison with buoy data when accounting for sampling. This will indirectly affect the budget-based DEEP-C product since erroneous wind speeds will influence the energy transports used in the calculation of surface fluxes; the precise influence is uncertain but has implications for budget-based indirect estimates of surface energy fluxes (Liu et al. 2017; Trenberth et al. 1995; Chiodo and Haimberger 2010; Mayer and Haimberger 2012; Trenberth and Fasullo 2017). Josey et al. (2014) found that assimilation of TAO mooring contributed to unrealistic near surface humidity and wind speed anomalies in ERAINT. The impact of these unrealistic anomalies on the latent heat flux in the tropical Pacific may play a role in the unrealistic $\mathrm{LH}$ trend. However, these results do not appear to contradict the mechanisms invoked to explain TEP cooling discussed by England et al. (2014) since this key region of wind enhancement centers on the central Pacific where satellite data and simulations broadly agree on recent changes. Nevertheless, the TEP is a key region in determining global climate variability and timevarying climate sensitivity (Ceppi and Gregory 2017; Andrews and Webb 2018) so understanding the role of surface fluxes in this region is crucial. While AMIP5 simulations are temporally homogeneous, they do not represent the key atmospheric feedbacks on ocean temperature so additional in-depth investigation is necessary to elucidate the mechanisms of decadal variability in ocean temperature, including using data from the ocean reanalysis and the fifth-generation ECMWF reanalysis (ERA5) for further comparisons and coupled reanalysis for feedback mechanism studies.
Acknowledgments. This work was supported by the Natural Environment Research Council (NERC) DEEP-C Grant NE/K005480/1 and SMURPHS Grant NE/N006054/1, the National Centre for Atmospheric Science, and the National Centre for Earth Observation. We acknowledge the ECMWF for providing ERAInterim data. We also acknowledge the teams making the JRA-55, MERRA2, AMIP5, SSM/I, CERES, and TAO data available. DEEP-C data are available online (http://dx.doi.org/10.17864/1947.111). We thank two anonymous reviewers for reviewing this paper and providing constructive comments and suggestions.

\section{REFERENCES}

Allan, R. P., 2017: Decadal climate variability and the global energy balance. PAGES, No. 25, 20-24, https://doi.org/10.22498/ pages.25.1.20.

_ C. Liu, N. G. Loeb, M. D. Palmer, M. Roberts, D. Smith, and P.-L. Vidale, 2014: Changes in global net radiative imbalance 1985-2012. Geophys. Res. Lett., 41, 5588-5597, https://doi.org/ 10.1002/2014GL060962.

Andrews, T., and M. Webb, 2018: The dependence of global cloud and lapse-rate feedbacks on the spatial structure of tropical Pacific warming. J. Climate, 31, 641-654, https://doi.org/ 10.1175/JCLI-D-17-0087.1.

Arora, V. K., and Coauthors, 2011: Carbon emission limits required to satisfy future representative concentration pathways of greenhouse gases. Geophys. Res. Lett., 38, L05805, https:// doi.org/10.1029/2010GL046270.

Balmaseda, M. A., K. E. Trenberth, and E. Källén, 2013: Distinctive climate signals in reanalysis of global ocean heat content. Geophys. Res. Lett., 40, 1754-1759, https://doi.org/10.1002/ grl.50382.

Bentamy, A., K. B. Katsaros, A. M. Mestas-Nuñez, W. M. Drennan, B. E. Forde, and H. Roquet, 2003: Satellite estimates of wind speed and latent heat flux over the global oceans. J. Climate, 16, 637-655, https://doi.org/10.1175/1520-0442(2003)016<0637: SEOWSA $>2.0 . \mathrm{CO} ; 2$.

Berrisford, P., P. Kållberg, S. Kobayashi, D. Dee, S. Uppala, A. J. Simmons, P. Poli, and H. Sato, 2011: Atmospheric conservation properties in ERA-Interim. Quart. J. Roy. Meteor. Soc., 137, 1381-1399, https://doi.org/10.1002/qj.864.

Bi, D., and Coauthors, 2013: The ACCESS coupled model: Description, control climate and evaluation. Aust. Meteor. Oceanogr. J., 63, 41-64, https://doi.org/10.22499/2.6301.004.

de Boisséson, E., M. A. Balmaseda, S. Abdalla, E. Källén, and P. Janssen, 2014: How robust is the recent strengthening of the tropical Pacific trade winds? Geophys. Res. Lett., 41, 43984405, https://doi.org/10.1002/2014GL060257.

Brown, P. T., W. Li, L. Li, and Y. Ming, 2014: Top-of-atmosphere radiative contribution to unforced decadal global temperature variability in climate models. Geophys. Res. Lett., 41, 51755183, https://doi.org/10.1002/2014GL060625.

Ceppi, P., and J. M. Gregory, 2017: Relationship of tropospheric stability to climate sensitivity and Earth's observed radiation budget. Proc. Natl. Acad. Sci. USA, 114, 13 126-13 131, https:// doi.org/10.1073/pnas.1714308114.

Chiodo, G., and L. Haimberger, 2010: Interannual changes in mass consistent energy budgets from ERA-Interim and satellite 
data. J. Geophys. Res., 115, D02112, https://doi.org/10.1029/ 2009JD012049.

Collins, W. J., and Coauthors, 2011: Development and evaluation of an Earth-system model-HadGEM2. Geosci. Model Dev., 4, 1051-1075, https://doi.org/10.5194/gmd-4-1051-2011.

Compo, G. P., and Coauthors, 2011: The Twentieth Century Reanalysis Project. Quart. J. Roy. Meteor. Soc., 137, 1-28, https:// doi.org/10.1002/qj.776.

Dee, D. P., and Coauthors, 2011: The ERA-Interim reanalysis: Configuration and performance of the data assimilation system. Quart. J. Roy. Meteor. Soc., 137, 553-597, https://doi.org/ 10.1002/qj.828.

Delworth, T. L., and Coauthors, 2006: GFDL's CM2 global coupled climate models. Part I: Formulation and simulation characteristics. J. Climate, 19, 643-674, https://doi.org/10.1175/ JCLI3629.1.

Dufresne, J. L., and Coauthors, 2013: Climate change projections using the IPSL-CM5 Earth System Model: From CMIP3 to CMIP5. Climate Dyn., 40, 2123-2165, https://doi.org/10.1007/ s00382-012-1636-1.

Easterling, D. R., and M. F. Wehner, 2009: Is the climate warming or cooling? Geophys. Res. Lett., 36, L08706, https://doi.org/ 10.1029/2009GL037810.

England, M. H., and Coauthors, 2014: Recent intensification of wind-driven circulation in the Pacific and the ongoing warming hiatus. Nat. Climate Change, 4, 222-227, https://doi.org/ 10.1038/nclimate2106.

Gelaro, R., and Coauthors, 2017: The Modern-Era Retrospective Analysis for Research and Applications, version 2 (MERRA-2). J. Climate, 30, 5419-5454, https://doi.org/ 10.1175/JCLI-D-16-0758.1.

Gent, P. R., and Coauthors, 2011: The Community Climate System Model version 4. J. Climate, 24, 4973-4991, https://doi.org/ 10.1175/2011JCLI4083.1.

Guemas, V., F. J. Doblas-Reyes, I. Andreu-Burillo, and M. Asif, 2013: Retrospective prediction of the global warming slowdown in the past decade. Nat. Climate Change, 3, 649-653, https://doi.org/10.1038/nclimate1863.

Hansen, J., M. Sato, P. Kharecha, and K. von Schuckmann, 2011: Earth's energy imbalance and implications. Atmos. Chem. Phys., 11, 13 421-13 449, https://doi.org/10.5194/ acp-11-13421-2011.

Hipel, K. W., and A. I. McLeod, 1994: Time Series Modelling of Water Resources and Environmental Systems. Elsevier, 1012 pp.

Huber, M., and R. Knutti, 2014: Natural variability, radiative forcing and climate response in the recent hiatus reconciled. Nat. Geosci., 7, 651-656, https://doi.org/10.1038/ngeo2228.

Josey, S. A., L. Yu, S. Gulev, X. Jin, N. Tilinina, B. Barnier, and L. Brodeau, 2014: Unexpected impacts of the tropical Pacific array on reanalysis surface meteorology and heat fluxes. $G e$ ophys. Res. Lett., 41, 6213-6220, https://doi.org/10.1002/ 2014GL061302.

Katsman, C. A., and G. J. van Oldenborgh, 2011: Tracing the upper ocean's missing heat. Geophys. Res. Lett., 38, L14610, https:// doi.org/10.1029/2011GL048417.

Kaufmann, R. K., H. Kauppib, M. L. Mann, and J. H. Stock, 2011: Reconciling anthropogenic climate change with observed temperature 1998-2008. Proc. Natl Acad. Sci. USA, 108, 790793, https://doi.org/10.1073/pnas.1102467108.

Klein, S. A., and D. L. Hartmann, 1993: The seasonal cycle of low stratiform clouds. J. Climate, 6, 1587-1606, https://doi.org/ 10.1175/1520-0442(1993)006<1587:TSCOLS>2.0.CO;2.
Knight, J., and Coauthors, 2009: Do global temperature trends over the last decade falsify climate predictions [in "State of the Climate in 2008"]? Bull. Amer. Meteor. Soc., 90, S22-S23.

Kobayashi, S., and Coauthors, 2015: The JRA-55 Reanalysis: General specifications and basic characteristics. J. Meteor. Soc. Japan, 93, 5-48, https://doi.org/10.2151/jmsj.2015-001.

Kosaka, Y., and S. P. Xie, 2013: Recent global-warming hiatus tied to equatorial Pacific surface cooling. Nature, 501, 403-407, https://doi.org/10.1038/nature12534.

Li, L., and Coauthors, 2013: The Flexible Global OceanAtmosphere-Land System Model, grid-point version 2: FGOALS-s2. Adv. Atmos. Sci., 30, 543-560, https://doi.org/ 10.1007/s00376-012-2140-6.

Liu, C., and Coauthors, 2015: Combining satellite observations and reanalysis energy transports to estimate global net surface energy fluxes 1985-2012. J. Geophys. Res. Atmos., 120, 9374 9389, https://doi.org/10.1002/2015JD023264.

__ , and Coauthors, 2017: Evaluation of satellite and reanalysisbased global net surface energy flux and uncertainty estimates. J. Geophys. Res. Atmos., 122, 6250-6272, https://doi.org/ 10.1002/2017JD026616.

Loeb, N. G., J. M. Lyman, G. C. Johnson, R. P. Allan, D. R. Doelling, T. Wong, B. J. Soden, and G. L. Stephens, 2012: Observed changes in top-of-atmosphere radiation and upper-ocean heating consistent within uncertainty. Nat. Geosci., 5, 110-113, https://doi.org/10.1038/ngeo1375.

Mayer, M., and L. Haimberger, 2012: Poleward atmospheric energy transports and their variability as evaluated from ECMWF reanalysis data. J. Climate, 25, 734-752, https:// doi.org/10.1175/JCLI-D-11-00202.1.

Meehl, G. A., J. M. Arblaster, J. Y. Fasullo, A. Hu, and K. E. Trenberth, 2011: Model-based evidence of deepocean heat uptake during surface-temperature hiatus periods. Nat. Climate Change, 1, 360-364, https://doi.org/ 10.1038/nclimate1229.

_, H. Teng, and J. M. Arblaster, 2014: Climate model simulations of the observed early-2000s hiatus of global warming. Nat. Climate Change, 4, 898-902, https://doi.org/10.1038/ nclimate2357.

Norris, J. R., and A. T. Evan, 2015: Empirical removal of artifacts from the ISCCP and PATMOS-x satellite cloud records. J. Atmos. Oceanic Technol., 32, 691-702, https://doi.org/ 10.1175/JTECH-D-14-00058.1.

Raddatz, T. J., and Coauthors, 2007: Will the tropical land biosphere dominate the climate-carbon cycle feedback during the twenty-first century? Climate Dyn., 29, 565-574, https:// doi.org/10.1007/s00382-007-0247-8.

Roberts, C. D., M. D. Palmer, R. P. Allan, D. G. Desbruyeres, P. Hyder, C. Liu, and D. Smith, 2017: Surface flux and ocean heat transport convergence contributions to seasonal and interannual variations of ocean heat content. J. Geophys. Res. Oceans, 122, 726-744, https://doi.org/10.1002/2016JC012278.

Schmidt, G. A., and Coauthors, 2014: Configuration and assessment of the GISS ModelE2 contributions to the CMIP5 archive. J. Adv. Model. Earth Syst., 6, 141-184, https://doi.org/ 10.1002/2013MS000265.

Scoccimarro, E., S. Gualdi, A. Bellucci, A. Sanna, P. G. Fogli, E. Manzini, M. Vichi, P. Oddo, and A. Navarra, 2011: Effects of tropical cyclones on ocean heat transport in a highresolution coupled general circulation model. J. Climate, $\mathbf{2 4}$ 4368-4384, https://doi.org/10.1175/2011JCLI4104.1.

Senior, C. A., and Coauthors, 2016: Idealized climate change simulations with a high-resolution physical model: HadGEM3-GC2. 
J. Adv. Model. Earth Syst., 8, 813-830, https://doi.org/10.1002/ 2015MS000614.

Singh, R., P. C. Joshi, and C. M. Kishtawal, 2005: A new technique for estimation of surface latent heat fluxes using satellitebased observations. Mon. Wea. Rev., 133, 2692-2710, https:// doi.org/10.1175/MWR2993.1.

Solomon, S., and Coauthors, 2010: Contributions of stratospheric water vapor to decadal changes in the rate of global warming. Science, 327, 1219-1223, https://doi.org/10.1126/science.1182488.

TAO Project Office, 2000: Tropical Atmosphere Ocean/Triangle Trans-Ocean Buoy Network. NOAA/PMEL, accessed 1 August 2015, http://www.pmel.noaa.gov/tao/data_deliv/deliv.html.

Taylor, K. E., R. J. Stouffer, and G. A. Meehl, 2012: An overview of CMIP5 and the experiment design. Bull. Amer. Meteor. Soc., 93, 485-498, https://doi.org/10.1175/BAMS-D-11-00094.1.

Trenberth, K. E., and J. T. Fasullo, 2013: An apparent hiatus in global warming? Earth's Future, 1, 19-32, https://doi.org/ 10.1002/2013EF000165.

- , and —, 2017: Atlantic meridional heat transports computed from balancing Earth's energy locally. Geophys. Res. Lett., 44, 1919-1927, https://doi.org/10.1002/2016GL072475.

_ J. W. Hurrell, and A. Solomon, 1995: Conservation of mass in three dimensions in global analyses. J. Climate, 8, 692-708, https://doi.org/ 10.1175/1520-0442(1995)008<0692:COMITD>2.0.CO;2.

Valdivieso, M., and Coauthors, 2015: An assessment of air-sea heat fluxes from ocean and coupled reanalyses. Climate Dyn., 49, 983-1008, https://doi.org/10.1007/s00382-015-2843-3.

Vila, D., D. R. Ferraro, and H. Semunegus, 2010: Improved global rainfall retrieval using the Special Sensor Microwave Imager (SSM/I). J. Appl. Meteor. Climatol., 49, 1032-1043, https:// doi.org/10.1175/2009JAMC2294.1.

Voldoire, A., and Coauthors, 2013: The CNRM-CM5.1 global climate model: Description and basic evaluation. Climate Dyn., 40, 2091-2121, https://doi.org/10.1007/s00382-011-1259-y.
Volodin, E. M., N. A. Dianskii, and A. V. Gusev, 2010: Simulating present-day climate with the INMCM4.0 coupled model of the atmospheric and oceanic general circulations. Izv., Atmos. Ocean. Phys., 46, 414-431, https://doi.org/10.1134/ S000143381004002X.

Von Schuckmann, K., and Coauthors, 2016: An imperative to monitor Earth's energy imbalance. Nat. Climate Change, 6, 138-144, https://doi.org/10.1038/nclimate2876.

Watanabe, M., H. Shiogama, H. Tatebe, M. Hayashi, M. Ishii, and M. Kimoto, 2014: Contribution of natural decadal variability to global warming acceleration and hiatus. Nat. Climate Change, 4, 893-897, https://doi.org/10.1038/ nclimate2355.

Watanabe, S., and Coauthors, 2011: MIROC-ESM 2010: Model description and basic results of CMIP5-20c3m experiments. Geosci. Model Dev., 4, 845-872, https://doi.org/10.5194/ gmd-4-845-2011.

Wentz, F. J., and R. W. Spencer, 1998: SSM/I rain retrievals within a unified all-weather ocean algorithm. J. Atmos. Sci., 55, 1613-1627, https://doi.org/10.1175/1520-0469(1998)055<1613: SIRRWA $>2.0 . \mathrm{CO} ; 2$.

Williams, K. D., and Coauthors, 2015: The Met Office Global Coupled model 2.0 (GC2) configuration. Geosci. Model Dev., 8, 1509-1524, https://doi.org/10.5194/gmd-8-1509-2015.

Yukimoto, S., and Coauthors, 2012: A new global climate model of meteorological research institute: MRI-CGCM3-Model description and basic performance. J. Meteor. Soc. Japan, 90A, 23-64, https://doi.org/10.2151/jmsj.2012-A02.

Zhang, Z. S., and Coauthors, 2012: Pre-industrial and mid-Pliocene simulations with NorESM-L. Geosci. Model Dev., 5, 523-533, https://doi.org/10.5194/gmdd-5-119-2012.

Zhou, C., M. D. Zelinka, and S. A. Klein, 2016: Impact of decadal cloud variations on the Earth's energy budget. Nat. Geosci., 9, 871-874, https://doi.org/10.1038/NGEO2828. 